\title{
Modern Holistic Medicine from the Perspective of Traditional Chinese Medicine
}

\author{
Ke He* \\ Faculty of International Studies, Prince of Songkla University, Thailand
}

Submission: June 7, 2019; Published: June 25, 2019

*Corresponding author: Ke He, Faculty of International Studies, Prince of Songkla University, Thailand

Abstract

The work presented in this paper aims to study modern holistic medicine from the perspective of traditional Chinese medicine and to elucidate the concept of holism in traditional Chinese medicine. Based on a secondary analysis of available literatures, the study findings have led the author to the conclusions that:

a. in spite of the superficial similarities, modern holistic medicine and traditional Chinese medicine are different in essence

b. the future architecture of modern holistic medicine should incorporate the thinking modes, clinical experience, treatment methods of traditional Chinese medicine, and these two medical systems can complement each other in the 21st century.

In addition, this paper also puts forward the suggestion of making full use of the current prosperity of wellness tourism in Thailand to promote Thai traditional medicine.

Keywords: Modern Holistic Medicine; Traditional Chinese Medicine; Wellness Tourism; Holism

\section{Introduction}

The development of science has deepened and increased humans' understanding of the natural world; but it may also cause humans to lose their systematic and overall cognition of the complex world. As a $21^{\text {st }}$ century science, complexity science calls for the transformation of scientific concepts and ways of thinking. It expands science away from linear, deterministic, and fixed traditional areas, into nonlinear, uncertain, and disorderly areas Yuan [1]. Nowadays, the emerging modern holistic medicine is based on the concepts and methods of complexity science, combining the concept of holism from ancient traditional medicines with the empirical methods of modern science. Being so central to the 'Holistic Medicine' therapies, holism involves an understanding that the body and mind are a unified system connected intimately and complexly to social, political-economic and biological systems, and a brief in the whole of these interconnected systems is greater than the sum of their parts Andrews et al. [2]. The concept of holism, which has existed in ancient times, is the core idea of modern systems theory, and it is also conceptually in line with traditional Chinese medicine (TCM). Based on a secondary analysis of available literatures, the current paper aims to study modern holistic medicine from the perspective of TCM and to elucidate the concept of holism of TCM. In addition, the current paper also suggests that modern holistic medicine should incorporate the integrated thinking mode of TCM into its future architecture. Lastly, this author also comes out with the suggestion of combining Thai
Traditional Medicine (TTM) with wellness tourism for the development of TTM.

\section{Modern Holistic Medicine}

\section{Definitions and Some History}

Holistic medicine is an umbrella term used to describe and include a varying number of therapies that attempt to treat the patient as a whole person. A more precise definition of the term is that holism is a philosophy that believes in treating the whole person and the integration of mind, body and spirit. Holism promotes the belief that these three elements of a human being must be treated together in order to achieve any notion of 'healing,' rather than simply treating a person for a specific illness or injury Mandel [3]. Holistic medicine looks at an individual's overall physical, mental, spiritual, and emotional well-being before recommending treatment; a practitioner with a holistic approach treats the symptoms of illness as well as looking for the underlying cause of the illness. Besides, Henderson [4] explained that holistic medicine is something that alternative medicine practitioners traditionally use as a basis for their treatments, but it is not just alternative or complementary medicine because holistic medicine does not dismiss conventional medicine (orthodox allopathic medicine).

Actually, holistic therapies existed very early in some ancient healing traditions, such as those from India and China, which date back over 5,000 years. In Western societies, clinical holis- 
tic medicine dates as far back as Hippocrates in ancient Greece around 300 BC Ventegodt et al. [5]. Hippocrates considered that many factors contribute to the health of a human being such as weather, nutrition, emotional factors; a host of different sources of pollution can interfere with health. For more than 2,000 years, this was what medicine was about in most of Europe. A holistic approach to patient care was also suggested by Thomas Percival in his book - Medical Ethics; or, a Code of Institutes and Precepts, adapted to the Professional Conduct of Physicians and Surgeons - first published in 1803 Henderson [4]. In recent centuries, Western medicine marched in unison with Western scientific progress. At the beginning of the twentieth century, the concept of holistic medicine fell out of favor in Western societies, with the advent of major advances in allopathic medicine. However, the term 'holistic' became part of everyday language again in the 1970s when Westerners began seeking an alternative to allopathic medicine. At present, modern holistic medicine is increasingly popular, and millions of people worldwide are turning to a more holistic approach to their healthcare.

\section{Ultimate Goal and Treatments}

According to the description given by the International Conference on Alternative and Traditional Medicine 2019, "the practice of holistic medicine integrates conventional and alternative therapies to prevent and treat disease and to promote optimal health. This condition of holistic health is defined as the unlimited and unimpeded free flow of life force energy through body, mind, and spirit. Holistic medicine encompasses all safe and appropriate modalities of diagnosis and treatment. It includes analysis of physical, nutritional, environmental, emotional, and spiritual and lifestyle elements. Holistic medicine focuses upon patient education and participation in the healing process. Holistic physicians embrace a variety of safe, effective options in the diagnosis and treatment, including education for lifestyle changes and self-care complementary alternatives; and conventional drugs and surgery".

The following three meanings can be interpreted from the description mentioned above. First of all, the ultimate goal of holistic medicine is to bring all areas of an individual's life, and most particularly the energy flowing through the body, back into harmony. Holistic medicine emphasizes optimal health (the body's natural state), proper nutrition and avoidance of substances such as chemicals that can pollute the body. Secondly, in terms of diagnosis, a patient is no longer seen as walking pathology, and holistic medicine considers the complete person physically, psychologically, socially and spiritually. Moreover, holistic diagnosis includes features unique to the individual (for example, disposition and personality) and not only those features shared by other patients with the same diagnosis Hill [6]. Anderson [7] comments that it is preferable to diagnose and treat patients as unique individuals rather than as members of a disease category; illness is viewed as a manifestation of a dysfunction of the whole person, rather than an isolated event. Thirdly, the practice of holistic medicine does not rule out the practice of allopathic medicine; the two can complement each other. In addition, there are no limits to the range of diseases and disorders that can be treated by holistic medicine, as the principle of holistic healing is to balance the body, mind, spirit, and emotions so that the person's whole being functions smoothly. So, when an individual seeks holistic treatment for a particular illness or condition, other health problems may improve without direct treatment, due to improvement in the performance of the immune system.

However, there is also suspicion and criticism about holistic medicine. For example, Charlton [8] argues that the path of holism leads to the medicalization of society as a result of the breakdown of boundaries between health and sickness because holism has no sense of where medicine should end, and the rest of life begins. Kelly [9] also states that medicine ought only to intervene where there is real or potential sickness; where it can do more good than harm. Although there has been such resistance to the holistic medicine paradigm, recent research has begun to accumulate powerful evidence of effective contributions to health promotion and healing from meditation, contiguous and remote healing, prayer, positive beliefs and attitudes, hope, humor, and unconditional love Anderson [7].

\section{Traditional Chinese Medicine}

\section{Brief Introduction}

Traditional Chinese medicine (TCM) originated from the legendary clan leader Fu Xi (2593 B.C.) period, established its theoretical system during the late years of the Warring States period to Chin and Han dynasties (475B.C.-A.D. 220) Luo [10]. Under the influence and guidance of classical Chinese materialism and dialectics, TCM has eventually evolved into a medical system with a unique theoretical system through long-term medical practice. The Chinese Committee for Terms in TCM defined TCM as "a broad range of medicine practices sharing common concepts which have been developed in China and are based on a tradition of more than 2,000 years, including various forms of herbal medicine, acupuncture, moxibustion, massage (tuina推拿), exercise (qigong 气功), and dietary therapy He k [11].

As Lin [12] argues, TCM has been under the influence of Confucianism and Taoism, but Taoism has a greater influence on TCM than Confucianism. Actually, TCM has absorbed a lot of enlightening ideas from theories of different schools of Ancient Chinese philosophy and Buddhism. TCM is a dialectical and dynamic system that integrates theories such as the theories of yin阴 \& yang 阳 (the positive and negative forces) and wuxing五行 (the Five Elements - wood, fire, earth, metal and water), and jingluo 经络 (Channels and Collaterals), of visceral manifestation, of treatment based on the differentiation of symptoms and signs, of pharmacology, of acupuncture and moxibustion, etc. Sizhen四诊 (observation, auscultation and olfaction, interrogation, palpation) are the principal four diagnostic methods of TCM; Bagang八纲 (eight principles- yin, yang, exterior表 and interior里, cold寒 and heat热, 
deficiency虚 and excess实) are important principles of treatment of TCM He k [11].

TCM emphasizes intervention before disease arises and often combines dietary advice, physical exercises such as Taijiquan, meditation, herbal medicines, massage, acupuncture and moxibustion, etc. The values of these individualized and integrated approaches are important directions for future public health Xu et al. [13] Huangdi Neijing 黄帝内经, the theoretical work on TCM, has summed up the medical achievements and clinical experiences since the Spring-Autumn Period and Warring States, establishing the unique theoretical system of TCM and laying the foundation for the development of TCM.

\section{Concept of Holism of TCM}

The concept of holism of traditional Chinese medicine comes from ancient Chinese philosophical thoughts; it adopts a comprehensive point-of-view of "time-space-human" to elucidate diseases; it emphasizes the coordination and unity among humans' social background, living conditions, mental psychology and quality of human life; it is a theory that studies the physiological pathology of the human body and the law of disease development from a philosophical stance Liang et al. [14] TCM is characterized by the concept of organic wholeness and treatment based on syndrome differentiation. The concept of holism permeates through all the fields in TCM, including physiology, pathology, diagnosis, syndrome differentiation and treatment. TCM's concept of holism has a deeper connotation. For example, wuzang五脏 (the five organs) in TCM refers to the five different overall "functional systems" in the human body, not only the five physical organs.

What needs to be emphasized is that the concept of holism of TCM has two meanings. On the one hand, TCM holds that the human body is an organic whole, and all the tissues and organs in the human body are in a unity that associate with each other and influence each other both physiologically and pathologically. The pathological changes in a certain part or region of the human body are usually related to the conditions of viscera, qi气 (vital energy) and blood, as well as yin and yang in the whole body. For example, findings from Luo [10] clearly indicate that the Treatise on the Secret Canon in the Imperial Library灵兰秘典论篇第八 of Huangdi Neijing has stated the respective functions as well as their relations of the twelve Viscera and Bowels. On the other hand, the human body, functioning as an integral entity, is also closely related to and should be in tune with the external environment. The unification of the human body and the external environment is also an important part of the holism of TCM. The human body communicates with the external environment constantly; factors such as climate, geographic location, working and family environments can all affect humans' health. The Treatise on Six Jie and Visceral Manifestation 六节藏象论第九 of Huangdi Neijing discusses that the alternation of the four seasons could bring favorable and unfavorable influences on the functional activities of the Viscera and Bowels. So TCM not only refers to the human body as an integral entity with all its components coordinating with and restraining each other in a harmonious way, but also realizes the relationship between the universe and the human being as an entity, with the influences of climatic changes to the human body and human's adaptability stemming from the joint physiological reflections of different parts and organs of the body Luo [10].

\section{Modern Holistic Medicine from The Perspective of Tcm}

As an emerging medicine, modern holistic medicine is closely interrelated with traditional medicines; many of the latter are reappearing in modern time as alternative, complementary and psychosocial medicines. And as mentioned in the current paper, in contrast to conventional medicine, which is largely based on analytical and reductionist approaches, both TCM and modern holistic medicine advocate holistic and relative approaches to thinking. In spite of the superficial similarities, modern holistic medicine and TCM are different in essence after all. From the perspective of TCM, the following three opinions about modern holistic medicine could be obtained.

\section{Modern systemism: Different holism to TCM}

It was Ludwig von Bertalanffy's theory of open systems that introduced the idea of a General Systems Theory (GST), which rose to prominence in the mid twentieth century and then helped to define the core principles of the systems approach along with the closely related field of cybernetics Ryan [15]. The basic methods of the systems approach are to treat the object under study as a system, analyze the structure and function of the system, and study the relationships between the system, its components and its environment. The objective of the systems approach is not only to understand the characteristics and laws of the system, but also to use them to control, manage, and transform the system; adjust the system structure; coordinate the relationships of various components; and make the system achieve the optimization targets. However, a system is more than just a set of components and their relationships.

The overall function of a system is the trait that each system element does not have in isolation. Ludwig Von Bertalanffy's emphasis on flows of energy and information into and out of an open system also brought attention to the environment of the open system. A system is defined as a complex whole that affects and is affected by its environment Ryan [15]. Modern holistic medicine treats the human body as a complex system and emphasizes the organic connection within the system. The body's components are seen as interdependent parts of the complex whole; illness is viewed as a manifestation of a dysfunction of the whole person, rather than an isolated event.

It is important that the systemism be distinguished from TCM's concept of holism. The latter is the way in which human beings deal with things when they are unable to investigate the internal details of things, while systemism is the way when humans have already understood the internal details after the analysis and research of the reductionism. Based on the holistic approach, 
the systems approach aims to demystify emergent properties by providing scientific understanding that utilizes analysis as well as synthesis, while TCM's concept of holism thinks highly of the grasp of the connections between external phenomena and emphasizes the unity of function and structure. So, both have their own merits. Contemporary science is showing the development trend of laying equal stress on experience and experiment, parts and whole. In the study of actual complex systems, scientists have now adopted a number of methods, such as metaphor, analogy and philosophical speculation. Yuan [1] contends that this shift in scientific paradigms has also bought about the re-examination of ancient forms of holistic science that primarily relied upon the methods of observation and mental dialectic analysis. Contemporary medicine is gradually evolving from the experimental medicine era to the holistic medical era; based on the systems approach, absorbing the essence of TCM's concept of holism, modern holistic medicine could go beyond analytical medicine and overcome the shortcomings of biomedicine.

\section{Ignores the correspondence between human and na- ture}

The body-spirit relationship and physician-patient relationship are particularly focused on by modern holistic medicine, and discussions and applications of relationships between the natural environment and human body seem fewer. According to TCM, excess psychological factors are known as qiqing 七情 (seven emotions), which include joy, anger, sadness, anxiety, worry, fear and fright. Each of the emotions interacts with particular internal organs and affects qi activities differently, leading to different disharmony patterns. Similar to TCM, modern holistic medicine considers the inseparability of body and spirit, advocates that the dimension of human consciousness is needed to be included, believes that every person could have immense potentials for self-healing, and education for lifestyle changes is necessary to treatment. In addition, modern holistic medicine promotes the ideal physician-patient relationship that considers the needs, de- sires, awareness, and insight of the patient as well as those of the physician. Findings from Anderson [7] clearly indicate that the quality of the physician-patient relationship is a major determinant of healing outcomes and holistic physicians encourage patients to evoke the healing power of love, hope, humor, and enthusiasm, and to release the toxic consequences of hostility, shame, greed, depression and prolonged fear, anger, and grief.

As to the relationship between human health and the natural environment, TCM has the so-called tianrenheyi 天人合一 (Harmony between human and nature) or tianrenxiangying 天人相 应 (Correspondence between human and nature) theory Zhang [16]. TCM holds that human beings are one of the components in nature and keeps close relationship with nature, so the human beings are in correspondence with nature. There is a mutual induction between the human beings and the natural environment with the invisible qi as the intermediary. The theory of correspondence between human and nature is used to explain the physiology and pathology of the body and to guide clinical diagnosis and treatment. For example, the correlations made between the climate and disease development is a particular way for TCM to explore the imbalance of the body. It facilitates physicians to identify the exogenous pathogens based on particular symptoms, regardless of identifying bacteria, viruses, toxins or parasites. Moreover, the doctrine of wuyunliuqi 五运六气 (five periods and six qi) explains relationships ancient Chinese observers assumed to exist between climate and a broad range of natural phenomena, including human health and illness Unschuld [17]. Instead of putting human in the overall context of nature to conduct research like TCM, modern holistic medicine pays less attention to the correspondence between human and nature and focuses on human's mental state and the social environment. It has been argued that optimal health of holistic medicine is the conscious pursuit for the highest qualities of the spiritual, mental, emotional, physical, environmental and social aspects of the human experience Anderson [7].

\section{Needs to incorporate thinking modes, theory and experience of TCM}

Table 1: The Five Elements and some Correspondence and Manifestations.

\begin{tabular}{|c|c|c|c|c|c|}
\hline Element & Wood & Fire & Earth & Metal & Water \\
\hline Directions & east & south & center & west & north \\
\hline Seasons & spring & summer & long summer & autumn & winter \\
\hline Climates & wind & heat & humidity & dryness & sold \\
\hline Flavours & sour & bitter & sweet & pungent & kidney \\
\hline Viscera & liver & heart & spleen & lung & head hair \\
\hline Body parts & nails & face/complexion & lips & body hair & nose \\
\hline Orifices & eyes & tongue & mouth & melancholy & fright \\
\hline Emotions & anger & joy & contemplation & ears \\
\hline
\end{tabular}

Nowadays, non-infectious chronic diseases (NCDs) have replaced the original dominant infectious diseases as the major global health threats to humans. These diseases, such as cardiovascular and cerebrovascular diseases, and tumors are complex diseases caused by unclear pathogens and multiple factors. Modern biomedicine, which is characterized by linear thinking and reduction analysis, has encountered difficulties in clarifying the overall characteristics of the complex life system and the laws of system activities. Besides, social development and technological progress have brought about new social diseases. As Yuan [1] discusses, people are aware of the fact that their health problems cannot be solved if they rely on the current medical system; and 
it is inevitable that modern medicine will choose to take a holistic approach, and will adopt something similar to Chinese medicine's model-based system.

The concept of holism is the cornerstone of the theoretical system of TCM. It not only focuses on the unity of body and mind, the unity of human and society, but the interaction between human and the natural environment. TCM can predict and prevent diseases by examining the interaction between the human body system and the natural environment. In addition, emphasizing relationships, attaching importance to universal connections, paying attention to dynamics are characteristics of TCM theory. Take the theory of Five Elements as an example. It advocates that all things in the universe are produced by the evolution of Five Elements. All elements and factors in the human body are not only produced by the evolution of Five Elements but also are represented by the Five Elements. Moreover, in view of the thinking mode of tian re nxiangying, the theory of Five Elements can also be used to explain the mutual correspondence and influence between human body and the nature. As shown in (Table 1) since the liver pertains to wood, spring is the best season to nourish the liver. Liver's prosperity can be manifested in the nails, and anger impairs the liver. The liver produces blood and the vital energy with its correspondence of sour flavor.

Obviously, modern holistic medicine has embodied a new medical model that combines "physiological-psychological-social-environmental". It still can transform into a more holistic model by incorporating the thinking modes, experience, theory and technology accumulated in TCM over thousands of years. It has been argued that the connotation in TCM theory will be elucidated along with the progression in science; meanwhile, the understandings in TCM help broaden the ideas in modern research Zhang et al. [18]. TCM has already achieved many positive results in treating diseases which modern biomedicine cannot; TCM practitioners have accumulated valuable clinical experience through many years of fighting against diseases. Thus, the future architecture of modern holistic medicine should incorporate the thinking modes, clinical experience, treatment methods of TCM, and actually these two medical systems can complement each other in this $21^{\text {st }}$ century.

\section{Discussions and Suggestion}

Ji [19] points out that the $21^{\text {st }}$ century is the era of Eastern culture, because the comprehensive thinking modes of Eastern culture can correct the shortcomings caused by Western culture. The mode of thinking is the foundation of all cultures. The Western mode is analytical; it overlooks the overall connection and is the root cause of such crises as environmental pollution, ecological imbalances, and the outbreak of new diseases. The Eastern mode is comprehensive and holistic, based on universal relations. Harmony between human and nature, the Chinese theory, is a typical Eastern thought. The comprehensive and holistic thinking mode of Eastern culture will replace the Western analytical thinking mode.

In the field of medicine, the emergence of modern holistic medicine follows that the development of biomedicine directed by the reductionist approach has encountered serious difficulties; it also seems to mean the "return" to traditional medicines. The optimal health of modern holistic medicine is much more than the absence of sickness; and according to holistic medicine, prevention is preferable to treatment and is usually more cost-effective. These are quite similar to the concept of TCM. However, after recognizing the overlap between these two medicines, this author maintains that modern holistic medicine and TCM are different in essence. For the convenience of readers to compare modern holistic medicine and TCM, this author sums up some important characteristics of these two medicines in Table 2. From the perspective of TCM, modern holistic medicine is based on modern systemism and different in concept of holism from TCM. Modern holistic medicine ignores the correspondence between human and nature, and it needs to incorporate thinking modes, clinical experience and the treatment methods of TCM in order to develop much further.

Table 2: Characteristics of Modern holistic medicine and TCM.

\begin{tabular}{|c|c|c|}
\hline Modern Holistic Medicine & TCM & Yin and yang, wuxing, jingluo \\
\hline Theoretical basis & Systemism, holism & Sizhen, bagang \\
\hline Diagnostic methods & Analysis of physical, nutritional, environmental, emotional, and spiritual and life- \\
style elements & \\
\hline Concept of holism & & \\
\hline
\end{tabular}

Look at an individual's overall physical, mental, spiritual, and emotional well-being before recommending treatment an overall holism including unity of human body and external environment, unity of function and structure within human body, unity of body and spirit, tianrenxiangying. Treatment A variety of safe, effective options including education for lifestyle changes, self-care complementary alternatives, and conventional drugs and surgery Decoction, Herbal medicine preparation, acupuncture and moxibustion, qigong, massage. However, Zhang [16] challenges the view that TCM's theoretical system is constructed under the guidance of the concepts, principles and conclusions of Chinese traditional philosophy. The rationality and profoundness of the philosophical concepts contained in TCM do not necessarily lead to the objectivity and truthfulness of TCM's theoretical knowledge. Besides, TCM was limited by historical conditions and scientific levels at that time; nowadays, the development of TCM needs to incorporate external observation using modern scientific technology Liu [20]. In addition, for the modernization of TCM, real innovations should include both TCM-inspired changes in modes of thinking and practices in western medicine and TCM refinements inspired 
by modern science Xu et al. [13]. So, in the long term, learning from each other or even confluence could be the future trend for both TCM and modern holistic medicine.

The rise of modern holistic medicine has offered a host of opportunities to Thai traditional medicine (TTM) as well. In Thailand's national healthcare system, Western medicine is now still in the mainstream and TTM has been integrated into the system as a traditional and alternative medicine [21-23]. As a Chinese person who has been in Thailand for more than ten years, this author also puts forward the suggestion of combining TTM with wellness tourism for the development of TTM. We are now in an age where people are more health conscious as NCDs and work stress have shown to have a greater impact on health. With the trend of heathy lifestyle, wellness tourism, which incorporates both the prevention and promotion of physical and mental health, has been growing rapidly all over the world. According to Pacific Prime Thailand, a registered insurance broker, the rate of annual growth in the wellness tourism market in Thailand averaged 7\% from 2013-2015, and the trend is set to continue. With its nature, food, herbs, traditional medicine, local sports, religions and tourism-friendly environment, Thailand offers more wellness opportunities at more competitive prices than European and American destinations. Particularly, treatments of TTM such as Thai massage, hot herbal compresses, and herbal steam baths provide a wealth of resources for wellness tourism. The global boom in the spa and wellness industry has not only kept the high demand for herbal products, but it has also created new job opportunities for TTM and tourism practitioners. So, the Thai government and its related departments could promote the development of TTM by making full use of the prosperity of wellness tourism.

\section{References}

1. Yuan B (2017) Holistic medicine: A new medical system based on body constitution and functional status. Journal of Traditional Chinese Medical Sciences 4(1): 3-9.

2. Andrews GJ, Evans J, McAlister S (2013) Creating the right therapy vibe: Relational performance in holistic medicine. Social Science \& Medicine 83: 99-109.

3. Mandel IS (2009) Understanding Differences Between Holistic, Alternative, and Complementary Medicine. Inquiries Journal /Student Pulse $1(10)$.

4. Henderson R (2014) Holistic medicine Patient 2: 12509.
5. Ventegodt S, Kandel I, Merrick J (2007) A Short History of Clinical Holistic Medicine. The Scientific World Journal 7: 1622-1630.

6. Hill A (1979) A visual encyclopedia of unconventional medicine: a health manual for the whole person. New English Library London.

7. Anderson RA (2001) Clinician's Guide to Holistic Medicine. McGraw-Hill New York.

8. Charlton BG (1993) Holistic medicine or the humane doctor? British Journal of General Practice 43: 475-477.

9. Kelly MP, Davies JK, Charlton BG (1993) Healthy cities: a modern problem or a post-modern solution? In: Davies JK, Kelly MP, eds. Healthy cities: research and practice Routledge, London.

10. Luo XW (2009) Introductory Study of Huangdi Neijing $1^{\text {st }}(\mathrm{edn})$ China Press of Traditional Chinese Medicine Beijing.

11. He K (2015) Traditional Chinese and Thai Medicine in a Comparative Perspective. Complementary Therapies in Medicine 23(6): 821-826.

12. Lin NJ (2011) Informal discussion of the development of modern medicine. Taiwan Medical Journal 54: 109-113.

13. Xu Q, Bauer R, Hendry BM, Fan TP, Zhao Z et al. (2013) The quest for modernization of traditional Chinese medicine. BMC Complementary and Alternative Medicine 13: 132.

14. Liang YX, Zhao X, Zhen XY (2014) Chinese Culture. Medicine $1^{\text {st }}($ edn) China Intercontinental Press Beijing.

15. Ryan A (2019) What is a systems approach?

16. Zhang ZM (2004) Discussion about the Influence of the Theory of Yin and Yang and Five Elements on the Development of Traditional Chinese Medicine. Science, Technology and Dialectics 21: 76-80.

17. Unschuld PU (2003) Huang Di Nei Jing Su Wen: Nature, Knowledge, Imagery in an ancient Chinese Medical Text. University of California Press London.

18. Zhang TX, Yan L, Ma SL, He J (2016) Human biological rhythm in traditional Chinese medicine. Journal of Traditional Chinese Medical Sciences 3(4): 206-211.

19. Ji XL (2015) Range for your eye over long vistas: Talking about traditional culture $1^{\text {st }}(\mathrm{edn})$ Chongqing: Chongqing Publishing Group.

20. Liu TJ (2018) The scientific hypothesis of an "energy system" in the human body. Journal of Traditional Chinese Medical Sciences 5(1): 29-34.

21. Reasons why the Wellness Tourism sector in Thailand is set to boom. Pacific Prime Thailand.

22. International Conference on Alternative and Traditional Medicine. Session 5 Holistic medicine.

23. Holistic Concept of Chinese Medicine. Integrated Chinese Medicine Holdings Ltd. 
This work is licensed under Creative

Commons Attribution 4.0 License

DOI: 10.19080/JYP.2019.07.555715
Your next submission with Juniper Publishers will reach you the below assets

- Quality Editorial service

- Swift Peer Review

- Reprints availability

- E-prints Service

- Manuscript Podcast for convenient understanding

- Global attainment for your research

- Manuscript accessibility in different formats

( Pdf, E-pub, Full Text, Audio)

- Unceasing customer service

Track the below URL for one-step submission

https://juniperpublishers.com/online-submission.php 